\title{
RELATIVE WEARING RESISTANCE OF VAPOR FRICTION ROTATION VACUUM PUMPS
}

\author{
Anton Zakharin, Anatoly Lebedev, Roman Pavlyuk, Pavel Lebedev
}

Stavropol State Agrarian University, Russia

anton-zaharin@mail.ru, lebedev.1962@mail.ru,roman_pavlyuk_v@mail.ru,zoya_lebedeva@mail.ru

\begin{abstract}
The results of a multifactor experiment for determining the relative wear resistance of the main and advanced friction pairs of vacuum pumps of the plate type are presented in the article, since they have received the most distribution in agriculture and industry. However, they have a number of shortcomings such as: low overhaul life and reduced productivity with increasing time of continuous operation. In connection with this, a number of design solutions have been developed to increase the efficiency of vacuum-type vacuum pumps. Since the introduction of these design solutions requires the use of new materials, it has become necessary to perform comparative tests of friction pairs of serial pumps and the modernized ones. For this purpose, a multifactor experiment was planned and carried out, and as factors of variation, the relative displacement speed of friction pairs, the pressure and the abrasive concentration in the contact zone were selected. After processing the data obtained as a result of the multifactorial experiment, regularities were obtained for wear of friction pairs "cast iron-textolite", "cast iron-fluoroplastic", "textolite-fluoroplastic", both under lubrication conditions and without it. From these dependencies, graphs were plotted: the relative wear resistance of these friction pairs of the velocity of relative displacement and pressure; the effect of lubrication in friction pairs on the relative wear resistance. Further, a detailed analysis of these graphs was made and conclusions were formulated.
\end{abstract}

Keywords: vacuum, pump, wear, friction, pressure.

\section{Introduction}

In agriculture and industry rotary-type machines of various designs are used, among which the most widely used are rotary vacuum pumps of plate type [1; 2]. In comparison with other devices, they are characterized by such advantages as: simplicity of design, small overall dimensions, uniformity in work, low cost. Among the most significant shortcomings of vacuum-type plate-type vacuum pumps, many researchers, both foreign and domestic, note a low overhaul life and a decrease in productivity with an increase in the time of continuous operation [3-6].

Therefore, we have developed a number of design solutions that make it possible to increase the efficiency of vacuum-type vacuum pumps [7]. Since the introduction of these design solutions requires use of new materials, it has become necessary to perform comparative tests of friction pairs of serial pumps and the modernized ones.

\section{Materials and methods}

The rate of wear of friction pairs was chosen as the optimization parameter (response function), therefore, it was decided to conduct a multi-factor experiment to determine the most optimal operating conditions, the materials of friction pairs of a vacuum pump of plate type and the degree of influence of individual parameters on wear resistance. The wear rate was determined for the following friction pairs: "cast iron-textolite", "cast iron-fluoroplastic", "textolite-fluoroplastic", both under lubrication conditions and without it.

To implement a multifactorial active experiment, a three-level plan of the second order of BoxBencin for three factors was adopted [8]. It belongs to the group of almost D-optimal plans, in which the dispersion of the reproducibility of the results of the experiment is uniformly distributed over all points of the response surface. The mathematical model of the second order, obtained on the basis of such plans, has the same statistical characteristic in all directions.

Based on our own theoretical studies and analysis of the research of the process of operation of rotary vacuum pumps by other authors, the following factors were adopted: the speed of relative displacement $v, \mathrm{~m} \cdot \mathrm{s}^{-1}$; pressure in the contact zone $P, \mathrm{MPa}$; concentration of abrasive Ca, \% [8].

\section{Results and discussion}

The processing of the experimental data obtained in the course of experimental studies allowed obtaining regression equations for the response function of the optimization parameter, which are polynomials of the first degree [7]. 


$$
\begin{gathered}
\gamma_{1}=0.2074-0.0048 v+0.0008 P+0.0032 C_{a}+0.0002 v P+0.0006 v C_{a}, \\
\gamma_{2}=0.0647-0.0015 v+0.0006 P+0.0013 C_{a}+0.0001 v P+0.0003 v C_{a}, \\
\gamma_{3}=0.0488-0.0013 v+0.0005 P+0.001 C_{a}+0.0001 v P+0.0002 v C_{a}, \\
\gamma_{4}=0.3604-0.0163 v+0.0013 P+0.0051 C_{a}+0.00045 v P+0.001 v C_{a}, \\
\gamma_{5}=0.1309-0.0046 v+0.001 P+0.002 C_{a}+0.0002 v P+0.0005 v C_{a}, \\
\gamma_{6}=0.0821-0.0028 v+0.0006 P+0.0016 C_{a}+0.0001 v P+0.0003 v C_{a},
\end{gathered}
$$

where $\gamma_{1}$-wear resistance of the friction pair "cast iron-textolite" with lubrication, $\mu \mathrm{m} \cdot \mathrm{h}^{-1}$;

$\gamma_{2}$ - wear resistance of the friction pair "cast iron-fluoroplastic" with lubrication, $\mu \mathrm{m} \cdot \mathrm{h}^{-1}$;

$\gamma_{3}$ - wear resistance of the friction pair "textolite-fluoroplast" with lubrication, $\mu \mathrm{m} \cdot \mathrm{h}^{-1}$;

$\gamma_{4}$ - wear resistance of the friction pair "cast iron-textolite" without lubrication, $\mu \mathrm{m} \cdot \mathrm{h}^{-1}$;

$\gamma_{5}$ - wear resistance of the friction pair "cast iron-fluoroplastic" without lubrication, $\mu \mathrm{m} \cdot \mathrm{h}^{-1}$;

$\gamma_{6}$ - wear resistance of the friction pair "textolite-fluoroplast" without lubrication, $\mu \mathrm{m} \cdot \mathrm{h}^{-1}$.

However, the greatest informativeness and validity in deciding on the choice of materials in friction pairs gives an estimate through the index of relative wear resistance, which are relations:

$$
k_{i j}=\frac{\gamma_{i}}{\gamma_{j}}
$$

where $k_{i j}$-index of relative wear resistance;

$\gamma_{i}$ and $\gamma_{j}$-values of the corresponding equations for fixed values of $v, P$ and $C_{a}, \mu \mathrm{m} \cdot \mathrm{h}^{-1}$.

The concentration of abrasive in friction pairs of running serial pumps is relatively constant and does not exceed the value of $C_{a}=5 \pm 1 \%$. Even with a thorough cleaning of the intake air, the friction zone is contaminated by the wear products that are retained by the lubricant. The increase in the concentration of abrasive in the friction pairs of the operating pump can occur, but only for a short time, since it cannot hold on to the surface of the part and is carried along with the outgoing air flow. Therefore, to analyze the obtained models of the rate of wear of friction pairs, the abrasive concentration is assumed to be $C_{a}=5 \%$.

According to the calculated data obtained with the help of the dependence (7), the graphs presented in Figures 1 and 2 are constructed.

The relativity parameters $k_{12}$ and $k_{13}$ express the ratio of the wear rate of the "cast iron-textolite" friction pair (1) to the friction pairs "cast iron-fluoroplastic" and "textolite-fluoroplastic" (2 and 3) with lubrication, and the $k_{45}$ and $k_{46}$ valuesexpress the ratio of the speed wear of the friction pair "cast iron-textolite" (4), respectively, to the friction pairs "cast iron-fluoroplastic" and "textolitefluoroplastic" (5 and 6) without lubrication.

The indicator $k_{12}$ characterizes the number of times the wear rate of the friction pair "cast irontextolite" decreases, when it is replaced by a pair of friction "cast iron-fluoroplastic". Analysis of the graph shows that the wear resistance of a friction pair at $v=2 \mathrm{~m} \cdot \mathrm{s}^{-1}$ will increase by 2.37-2.55 times depending on the pressure $\mathrm{P}$, and at a velocity $v=15 \mathrm{~m} \cdot \mathrm{s}^{-1}$ it will increase by 2.35-2.45 times.

For the indicator $k_{13}$, these indicators at $v=2 \mathrm{~m} \cdot \mathrm{s}^{-1}$, will be equal to $2.98-3.23$, and for $v=15 \mathrm{~m} \cdot \mathrm{s}^{-1} 2.91-3.07$ depending on the pressure $\mathrm{P}$.

For the indicator $\mathrm{k}_{45}$, these indicators at $v=2 \mathrm{~m} \cdot \mathrm{s}^{-1}$ will be equal to 2.18-2.29 depending on the pressure $\mathrm{P}$, and at $v=15 \mathrm{~m} \cdot \mathrm{s}^{-1}$ they will all give an increase in wear resistance by 1.92 times.

For $k_{46}$, these indices at $v=2 \mathrm{~m} \cdot \mathrm{s}^{-1}$ will be equal to 3,32-3,52 depending on the pressure $\mathrm{P}$, and at $v=15 \mathrm{~m} \cdot \mathrm{s}^{-1}$ they will all give an increase in wear resistance by 2.98 times.

The following patterns should be noted, revealed during the analysis of the graphs (Fig. 1):

1. The wear resistance of the friction pair "cast iron-textolite" is lower than the wear resistance of friction pairs "cast iron-fluoroplastic" and "textolite-fluoroplastic", both with lubricant and without it. This is because textolite has a fibrous structure, so that its working surface becomes softer during the wear process and the area of the actual contact increases, decreasing the specific pressure in the contact zone. 
2. All the dependencies obtained are not linear. This is due to the fact that in friction pairs with fluoroplastic, an increase in the speed of relative displacement of the mating surfaces gives a greater increase in the wear rate than in the friction pair "cast iron-textolite".

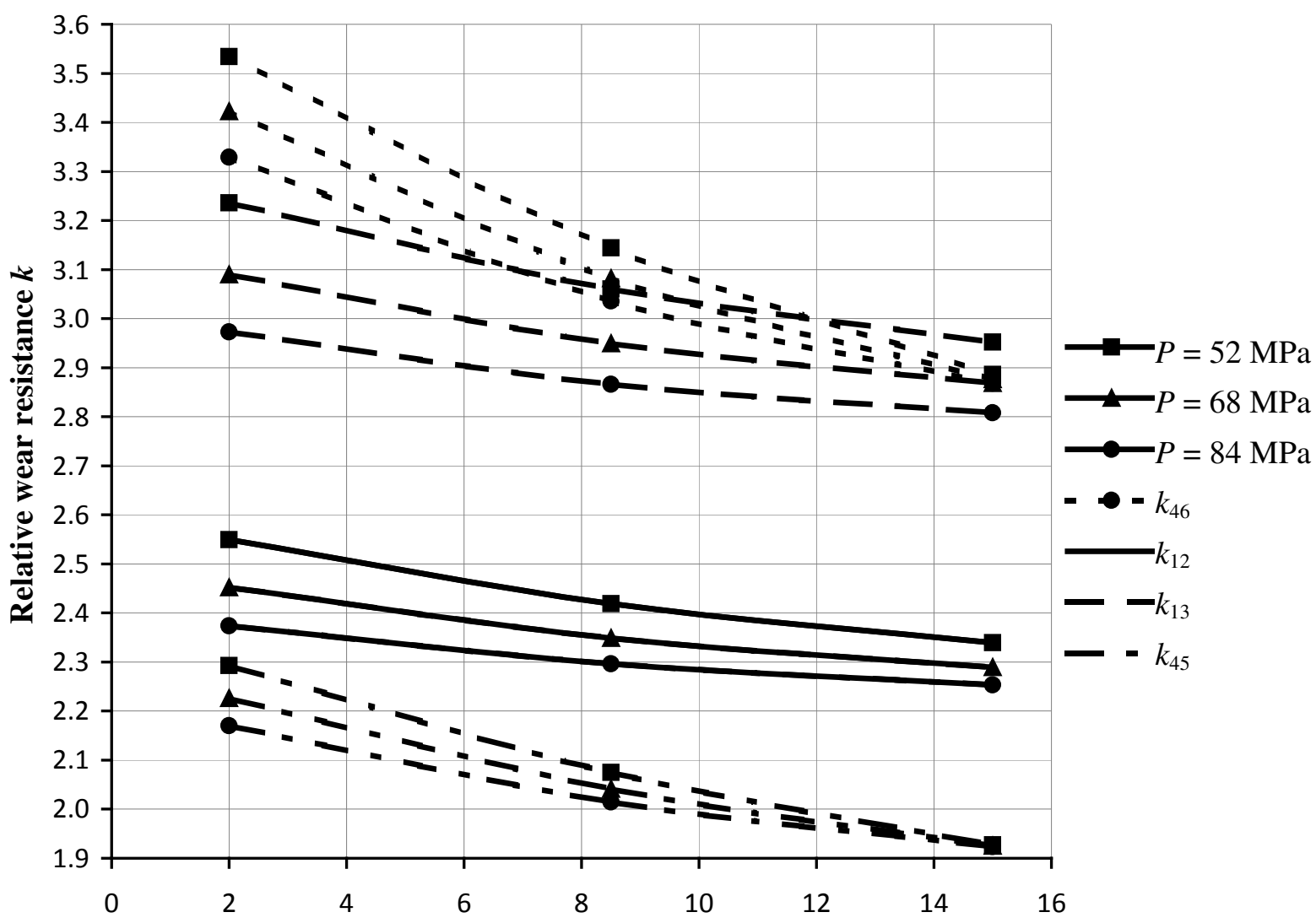

Speed of relative displacement $\mathrm{v}, \mathrm{m} \cdot \mathrm{s}^{-1}$

Fig. 1. Dependences of relative wear resistance of pairs of friction "cast iron-fluoroplastic" and "textolite-fluoroplastic" to wear resistance of "cast iron-textolite" friction pair on relative displacement velocity $v$ and pressure $P$

3. The parameters $k_{12}$ and $k_{13}$ decrease less intensively with an increase in the relative displacement speed from 2 to $15 \mathrm{~m} \cdot \mathrm{s}^{-1}$ than the $k_{45}$ and $k_{46}$. This is due to the fact that in the friction pairs described by the indices $k_{12}$ and $k_{13}$ there is a lubricant, which with an increase in the speed of relative displacement, reduces the degree of contact of rubbing surfaces, thereby increasing their wear resistance.

4. The influence of pressure on the relative values of $k_{12}$ and $k_{13}$ friction pairs with lubrication, with an increase in speed up to $15 \mathrm{~m} \cdot \mathrm{s}^{-1}$, is more significant than for the parameters of frictionless friction pairs $k_{45}$ and $k_{46}$. This is explained by the fact that in the friction pairs with "cast ironfluoroplastic" and "textolite-fluoroplast" lubricants, the lubricant levels the contacting surfaces by dividing them, which together with the pressure increase further increases the area of their actual contact, compensating for its negative effect on wear resistance. In friction pairs without lubrication, the negative pressure effect is not compensated for by anything, so increasing the pressure intensifies the wear process, thereby reducing the relative wear resistance.

The parameters $k_{14}, k_{25}, k_{36}$ express the ratio of the wear rate of friction pairs with lubrication $(1,2$ and 3), respectively, to friction pairs without it $(4,5$ and 6$)$.

Figure 2 shows the dependences of the coefficients $k_{14}, k_{25}, k_{36}$ on the velocity of relative displacement $v$ and pressure $\mathrm{P}$ at an abrasive concentration of $C_{a}=5 \%$ for the friction pairs studied.

The indicator $k_{14}$ characterizes the number of times the wear rate of the friction pair "cast irontextolite" without lubrication increases. Analysis of the graph shows that the wear resistance of this 
friction pair at speed $v=2 \mathrm{~m} \cdot \mathrm{s}^{-1}$ will decrease by $38.5 \%$, and at a speed of $v=15 \mathrm{~m} \cdot \mathrm{s}^{-1}$ it will decrease by $26-29 \%$, depending on the pressure.

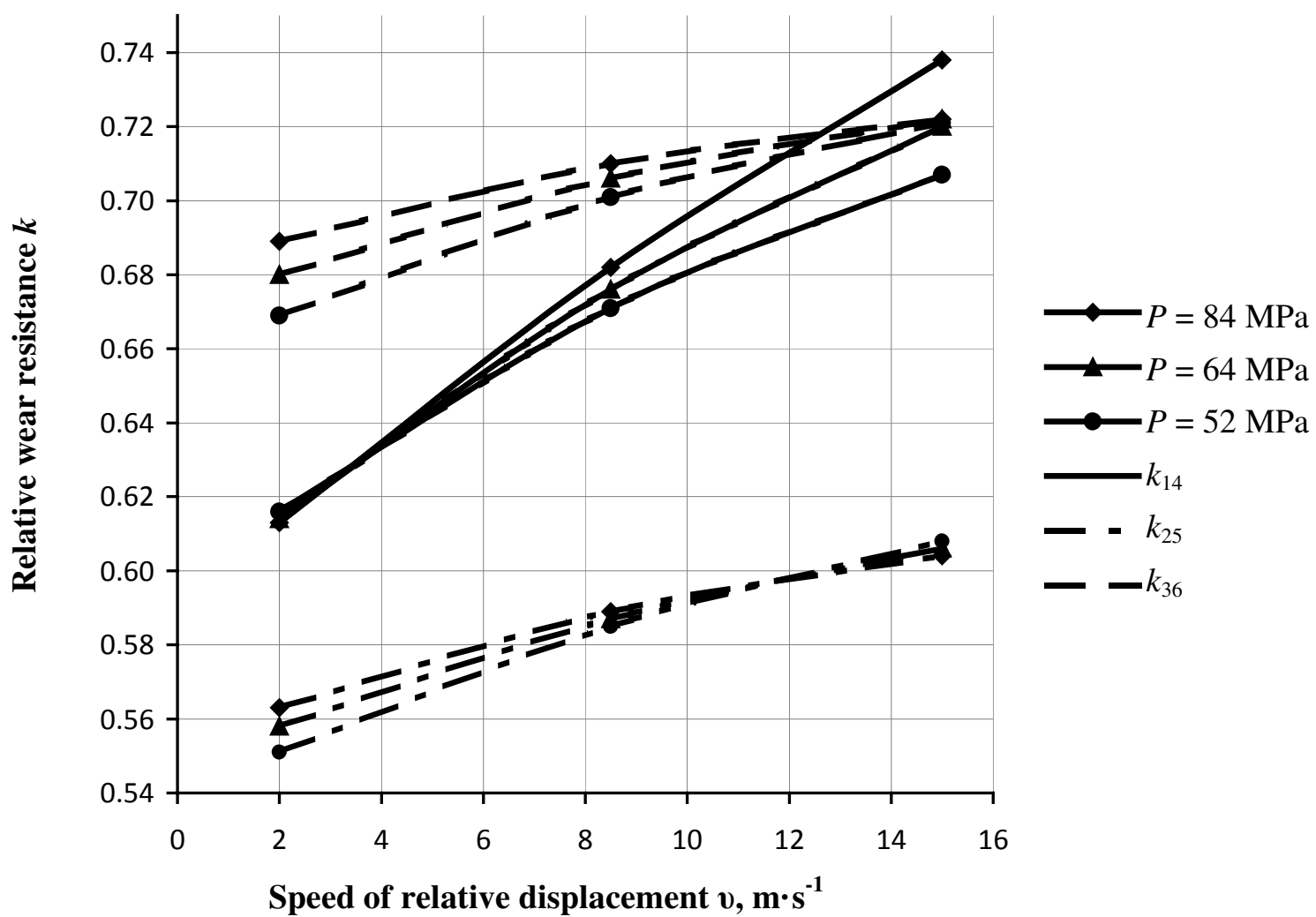

Fig. 2. Effect of lubricant in friction pairs "cast iron-textolite", "cast iron-fluoroplastic" and "textolite-fluoroplastic" on relative wear resistance

The $\mathrm{k}_{25}$ index characterizes the friction pair "cast iron-fluoroplastic" and shows that the wear resistance of this friction pair at speed $v=2 \mathrm{~m} \cdot \mathrm{s}^{-1}$ will decrease by $43.5-45 \%$, depending on the pressure, and at a speed of $v=15 \mathrm{~m} \cdot \mathrm{s}^{-1}$ it will decrease on $39 \%$.

Coefficient k36 characterizes the wear resistance of the friction pair "textolite-fluoroplast", and at a concentration of abrasive $C_{a}=5 \%$ and a velocity $v=2 \mathrm{~m} \cdot \mathrm{s}^{-1}$ it will decrease by 31-33\%, depending on the pressure, and for the same abrasive concentration and velocity $v=15 \mathrm{~m} \cdot \mathrm{s}^{-1}$ will decrease by $28 \%$.

The following patterns should be noted, revealed during the analysis of the graph (Fig. 2):

1. The lack of lubrication has a maximum effect (39-45\%) on the reduction of the relative wear resistance in the friction pair "cast iron-fluoroplastic". This is due to the fact that, in the absence of lubrication, irregularities on the surface of cast iron act as "saws", grinding off the surface of a softer fluorineplast, and in the presence of lubrication, the surface of the cast iron is leveled, reducing the rate of wear.

2. All the dependencies obtained have a deflection (not straight lines). This is due to the fact that, in friction pairs with lubrication, an increase in the speed of relative displacement of the mating surfaces gives a greater increase in the rate of wear than in frictionless pairs (in the considered speed range), due to the abrasive retaining a layer of lubrication, which increases the wear rate of the contacting surfaces .

3. In the friction pairs with fluoroplastic, the relative wear resistance increases less intensively with increasing speed than in the "cast iron-textolite" friction pair, because the increase in the speed of the moving parts reduces the number of elastic deformations in the PTFE, thereby increasing the surface wear. 


\section{Conclusions}

Thus, the conducted studies have shown that the pairs of friction "cast iron-fluoroplastic" and "textolite-fluoroplast" have a lower wear rate compared with the pair of friction "cast iron-textolite" on average with lubrication of 2.3 and 2.9 times, respectively, and without lubrication 2 and 3.1 times for all modes considered. The use of fluoroplast-4 material is promising as a material for the surfaces of friction pairs of rotary vacuum pumps.

\section{References}

[1] Мжельский Н.И. Вакуумные насосы для доильных установок. Москва: Машиностроение, 1974. 151 c. (MzhelskyN.I. Vacuum pumps for milking plants. Moscow: Mechanical Engineering, 1974. 151 p.) (In Russian).

[2] Berges H. Oil-free vacuum pumps of compact design.Vacuum, 1988. № 8. pp. 761-763.

[3] Umrath W. Fundamentals of Vacuum Technology. Cologne, 2007. 194 p.

[4] Wycliffe H. Rotary pumps and mechanical boosters -as used on today's high vacuum systems, Vacuum № 37,1987. pp. 603-607.

[5] Audi M., de Simon M. Ion pumps/ Vacuum № 37,1987.pp. 639-636.

[6] Heppell T.A. High vacuum pumping system-an overview. Vacuum № 37, 1987, pp. 593-601.

[7] Лебедев А.Т., Захарин А.В. Надежность и эффективность вакуумных насосов: монография.Ставрополь, 2011. 121 c. (Lebedev A.T., ZakharinA.V.Reliability and efficiency of vacuum pumps: monograph. Stavropol, 2011. 121 p.) (In Russian).

[8] Мельников С. В., Алешкин В. Р., Рощин П. М. Планирование эксперимента в исследованиях сельскохозяйственных процессов. Изд. 2-еперераб. идоп. - Ленинград: Колос, 1980. 168 с. (Melnikov S.V., Aleshkin V.R., Roshchin P.M. Planning of the experiment in the research of agricultural processes. Ed. 2-nd revision. and additional. - Leningrad: Kolos, 1980. 168 p.)(In Russian). 